Transportation Research Forum

Freeway Speeds and Speed Variations Preceding Crashes, Within and Across Lanes Author(s): Kara M. Kockelman and Jianming Ma

Source: Journal of the Transportation Research Forum, Vol. 46, No. 1 (Spring 2007), pp. 43-61

Published by: Transportation Research Forum

Stable URL: http://www.trforum.org/journal

The Transportation Research Forum, founded in 1958, is an independent, nonprofit organization of transportation professionals who conduct, use, and benefit from research. Its purpose is to provide an impartial meeting ground for carriers, shippers, government officials, consultants, university researchers, suppliers, and others seeking exchange of information and ideas related to both passenger and freight transportation. More information on the Transportation Research Forum can be found on the Web at www.trforum.org. 


\title{
Freeway Speeds and Speed Variations Preceding Crashes, Within and Across Lanes
}

\author{
by Kara M. Kockelman and Jianming Ma
}

Relationships between speed choice and crash occurrence have been difficult to identify. This work examines vehicle speeds (and their variations) derived from single loop detectors for several Southern California freeways, within and across freeway lanes, together with corresponding crash data. While a variety of factors clearly influence speed and speed variance, there is no evidence in these crash data sets, and observations of their corresponding series of 30-second traffic conditions, that speeds or their variation trigger crashes.

\section{BACKGROUND}

In the United States and elsewhere, traffic crashes claim more human years than any other incident or disease. They also result in tremendous property losses. U.S. crash costs for the year 2000 are estimated to well exceed $\$ 200$ billion, with roughly a quarter of this from property damage (Blincoe 2002). U.S. crashes claimed 42,636 lives in 2004 (USDOT 2005). Driver behavior, roadway design, weather and other factors all play a role in crashes. The most debated component is probably driver behavior in the form of speed choices. While it is well understood that higher impact speeds produce more severe crashes (Joksch 1993, Kockelman and Kweon 2002, and Kockelman et al. 2006), it is not altogether clear what roles speed variation (across vehicles/drivers) and speed limit policies play (Lave 1985, Lave and Elias 1994, Johansson 1996, Aljanahi et al. 1999, Farmer et al. 1999, Davis 2002, Ossiander and Cummings 2002, Navon 2003, and Vernon et al. 2003). To this end, this paper focuses on the effect driver behavior has in creating crashes in the form of speed choice - while controlling for roadway design features and weather conditions.

\section{LITERATURE REVIEW}

The speed-crash literature provides a valuable background for the debate, and motivates the questions at the heart of this research. In the 1960's Solomon (1964) and Cirillo (1968) found that many vehicles involved in rural and interstate highway crashes were traveling well above or below the average speed. They did not control for access point densities, however. Access points introduce practically stopped vehicles to the traffic stream, resulting in very dangerous conditions on highspeed roadways. They also presumed their sampled speed data to apply to long roadway sections at all times of day. Lave (1985) cited their work when using models of aggregate speed and crash data to conclude that highway fatality rates depend more on speed variance (across vehicles) than on average speeds. However, Davis (2002) has clearly demonstrated how aggregate relationships between speed, speed variance and crash frequency are not necessarily supported by the underlying, disaggregate data.

Garber and Gadiraju (1989) investigated how differences in design speeds and posted speed limits influence speed choices. They found minimal speed variation (with speed standard deviations on the order of $7.55 \mathrm{mph}$ ) when posted speed limits were $10 \mathrm{mph}$ below design speeds, and essentially constant speed variation, regardless of the difference in posted and design speeds. They also found that drivers chose higher speeds on roadways with better geometric design, irrespective of posted speed limits, and concluded that higher speeds do not necessarily result in higher crash rates, whereas higher speed variation does. 
Using data from rural highways with speed limits 80 kilometers per hour $(\mathrm{km} / \mathrm{h})$ or above in Adelaide, Australia, Kloeden et al. (2001) estimated that a vehicle's risk of involvement in an injurious crash doubles when traveling just six miles per hour $(\mathrm{mi} / \mathrm{h})(10 \mathrm{~km} / \mathrm{h})$ above the roadway's average speed. This risk multiplier rises to six when traveling $12 \mathrm{mi} / \mathrm{h}(20 \mathrm{~km} / \mathrm{h})$ above the average speed. They concluded that reductions in average speeds would be more helpful in reducing the risk of crash involvement than reductions in speed difference. Just one year later, using data from urban highways, Kloeden et al. (2002) concluded that differences in crash involvement arise mainly due to actual speeds at which drivers choose to operate their vehicles, instead of other factors, like driver type and speed variations. However, they were unable to control for these other variables.

Golob et al. (2003c) obtained crash and nearby single-loop detector ${ }^{1}$ data for all crashes reported along six freeways in California's Orange County in 1998. They distinguished eight traffic flow regimes based on speed variation and found the highest crash rates (6.3 crashes per million vehicle miles traveled (VMT) during the morning peak period) during heavily congested flow, corresponding to low mean speeds, low speed variation, low flows, and low flow variation. In contrast, the lowest crash rates ( 0.6 per million VMT) appeared as morning-peak traffic approached capacity conditions, characterized by high speeds and low speed variation. However, in order to avoid "assumptions of uniform speed, average vehicle length, and ... the physical installation of each loop (detector)" Golob et al. (2003c p. 3), used the ratio of 30-second volume-to-occupancy as a proxy for speed ${ }^{2}$. In addition, they characterized "speed variation" as the difference between the $90^{\text {th }}$ and $50^{\text {th }}$ percentile values of speed estimates during the 27.5 minutes preceding each crash. Thus, the presence of long vehicles (such as commercial trucks) will reduce speed estimates, and the measure of variation is far from instantaneous. If truck presence and/or local speed variations are important crash factors, these speed estimates will not capture such effects.

In summary, based on a review of the literature, data and methodological limitations have prevented a resolution of the speed-crash debate. This research employs some new methods, using a subset ${ }^{3}$ of Golob et al.'s data set. 30-second detector data from single loops, paired with effective vehicle length assumptions, roadway conditions, and crash data result in estimates of instantaneous speed variation within and across lanes. These permit models based on more disaggregate information, and allow one to ascertain the effects of various design variables, such as number of lanes, lane location, and lighting conditions.

\section{DATA DESCRIPTION}

The data set used in this work involves crashes that occurred in January 1998 on six Orange County, California, freeways: Interstates 5 and 405, and State Routes 22, 55, 57, and 91. Crash-specific data were acquired from Caltrans’ Traffic Accident Surveillance and Analysis System (TASAS) database and assembled by Golob and Recker (2002). Golob and colleagues compiled and have used the entire 1998 year's data set in several studies of traffic crash typology (Golob and Recker 2002 and 2003, Golob et al. 2003a and 2003b).

The January 1998 database subset contains all 744 crashes that resulted in police reports, and 55 of these resulted in injury or death; these are the subject of this investigation. The database also contains basic traffic flow data for 30 minutes preceding each crash. These were derived from single-loop detectors upstream ${ }^{4}$ and within 2,000 feet of the crash mile-post locations. ${ }^{5}$

Recognizing actual crash times are not known precisely and traffic conditions existing several minutes prior to a crash probably have little effect on the crash's occurrence, Golob and Recker (2002) discarded the 2.5 minutes of traffic data immediately preceding each crash's reported time. This strategy also was employed here, resulting in the removal of five 30-second ( $\mathrm{sec}$ ) intervals from each 30-minute period of traffic condition data that accompanies every crash record.

In addition, the algorithm for within-lane speed variance estimation (discussed in the following section) results in the loss of the first two 30 -sec traffic observations at each loop detector. Thus, there remain 53 usable sequential 30-sec observations preceding each crash. After accommodating a 
small portion (less than 2\%) of observations with incomplete detector data 2,858 30-second roadway section observations remained. All roadway sections in the data set contain from three to five (oneway) lanes, resulting in 12,243 30-second lane observations. Therefore, statistical results are based on either the section-specific 2,858 observations, or the lane-specific 12,243 observations.

The loop detector data provide information on lane number, occupancy, volume, and time of day. The crash reports provide information on lighting, pavement surface, and other crash conditions. And the FHWA's Highway Safety Information System (HSIS) data set (FHWA 2000) provided design speeds for the detector locations. ${ }^{6}$ All these factors, along with lane location, presence of obstructions, and other readily available variables were controlled for in the models that follow. However, before applying such models, flow and occupancy had to be translated into robust estimates of speed and speed variance.

\section{ESTIMATION OF SPEED \& SPEED VARIANCE}

In 1998, the six freeways under study were instrumented with single inductive loop detectors. Single loops provide only two measures of traffic conditions: ${ }^{7}$ traffic counts (the number of vehicles registered as passing over the loop detectors) and occupancy (the fraction of time the loop's detection zone is occupied by a vehicle). Speed estimates require vehicle length and detection zone length assumptions. Speed variance estimates (across individual vehicles, both within and across lanes) require assumptions regarding speed distributions and their temporal stability. The methods of estimation used in this work are standard for average speed and novel for speed variance.

\section{Estimation of Average Speeds}

Under an assumption of zero acceleration (or deceleration), ${ }^{8}$ a vehicle's speed is the ratio of the distance it travels and its travel time. A single vehicle passing over a presence-type detector ${ }^{9}$ travels a distance equal to the vehicle length $\left(l_{i}\right)$ plus the effective detection zone length ${ }^{10}\left(l_{d}\right)$ during the detector's occupancy time $\left(t_{i}\right)$. The speed formula is thus as follows:

$$
v_{i}=\frac{3600}{5280}\left(\frac{l_{i}+l_{d}}{t_{i}}\right)
$$

where $v_{i}=$ speed of individual vehicle $i$ (miles per hour), $l_{i}=$ length of vehicle (feet), $l_{d}=$ effective loop detector length (feet), and $t_{i}=$ detector occupancy time (seconds).

Many vehicles can traverse a detector during a 30-second interval. The average speed during any such interval can be computed using Equation 2:

$$
\bar{v}=\frac{\sum v_{i}}{N}=\frac{3600}{5280}\left(\frac{\sum\left(l_{i}+l_{d}\right) / t_{i}}{N}\right) \approx \frac{3600}{5280} \times \frac{\sum\left(l_{i}+l_{d}\right)}{\sum t_{i}}
$$

where $\bar{v}$ is average speed and $N$ is the number of vehicles traversing the detector during the 30 -sec interval.

The final part of Equation 2 is only an approximation. It holds exactly if the individual speeds are constant/equal during the interval. 
Freeway Speeds

Assuming constant speeds, average occupancy times $\left(\bar{t}_{o}\right)$ and vehicle lengths $\left(\bar{l}_{v}\right)$ may be used to form the following average speed equation:

$$
\hat{\bar{v}}=\frac{3600}{5280}\left(\frac{\bar{l}_{v}+l_{d}}{\bar{t}_{o}}\right)
$$

For a 30 -second period, with constant speeds and an occupancy fraction ${ }^{11}$ of $\% O C C_{i, t}$, the average vehicle speed can be estimated using the following expression:

$$
\hat{\bar{v}}_{l, t}=\frac{n_{l, t}}{30 / 3600}\left(\frac{100}{\% O C C_{l, t}}\right) \frac{\bar{l}_{l, t}+l_{d}}{5280}
$$

where $\hat{\bar{v}}_{l, t}$ is the average speed estimate, $\mathrm{n}_{l, t}$ is the number of vehicles and $\bar{l}_{l, t}$ is the average vehicle length during the $t^{\text {th }} 30$-second interval in the $t^{\text {th }}$ lane.

Unfortunately, the effective vehicle length $\left(\bar{l}_{v}+l_{d}\right)$ is not known. Much research has addressed estimation of vehicle speeds using single loop detector data. (See, for example, Pushkar et al. 1994, Wang and Nihan 2000 and 2003, Coifman et al. 2003, Coifman 2001, and Bruce 2002.) All require strong assumptions, and/or more data than are available. ${ }^{12}$

After some initial and very disappointing ${ }^{13}$ work using effective loop- and vehicle-length assumptions of 10 feet and 14.75 feet, respectively (in order to estimate speeds based on occupancy and count data), local "g factors" were used. These are estimates of total effective lengths $\left(l_{v}+l_{d}\right)$, as provided by the Performance Measurement System (PeMS) group at the University of California, Berkeley, and based on historical data for every 5-minute period of every day of the year at every detector station in the system. (Jia et al. 2001, PeMS 2002) They are based on free-flow-speed assumptions during uncongested periods. (Chen et al. 2002) Figure 1 summarizes the g-factor (vehicle length) values used here, and Table 1 provides g-factor values for example sections and times of day. While these g-factors typically provide very reasonable average speed estimates, the methods of their derivation are not entirely known. Based on these g-factors, Equation 4 offers estimates of the time-mean speed for each station, in every 30-second interval and every lane. Vehicle count-weighted averages of these lane-based speed averages provided road section speed averages, recognizing all lanes. Both within-lane and section speed averages were modeled, and are key inputs to the speed variance estimates described below.

\section{Estimation of Speed Variation}

Along with average travel speeds, speed variations may play important roles in crash occurrence and severity. But disaggregate estimates, of instantaneous variation, are needed; and these are difficult to obtain, without individual speed measurements. In this work, estimates of within-lane speed variation rely on the within-lane average speed estimates, while across-lane and total section speed variance estimates rely on both within-lane and section average speeds.

To transform a series of 30-second speed averages into estimates of instantaneous speed variation, a strong assumption is needed; speed distributions, and thus speed variance, vary little across every five consecutive 30 -second intervals. Because significant shifts in traffic conditions generally occur on the order of hours (such as peak to off-peak periods of demand), this assumption of steady traffic conditions during each 2.5-minute interval seems quite reasonable. The observed variation in 30-second average speeds, around the 150-second interval's grand mean $\left(\overline{\bar{v}}_{150 \text { sec } l, t}\right)$ can then be used to approximate the underlying speed distribution's overall variation. 
Figure 1. Frequency Distribution of g-Factors (i.e., mean effective vehicle lengths)

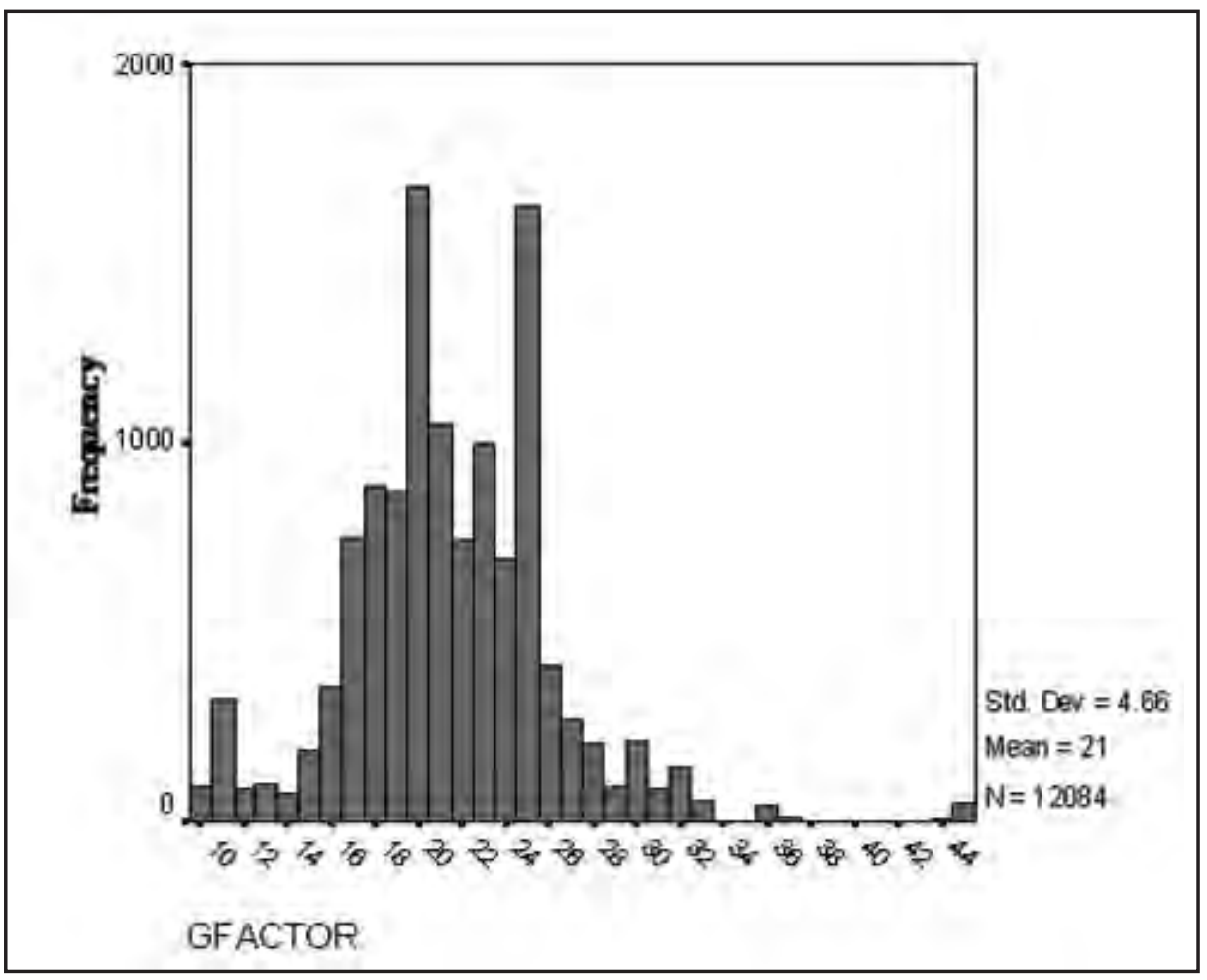

These computations rely on the following equations:

$$
\overline{\bar{v}}_{150 \mathrm{sec} l, t}=\frac{n_{l, t-2} \hat{\overline{\bar{v}}}_{l, t-2}+n_{l, t-1} \hat{\bar{v}}_{l, t-1}+n_{l, t} \hat{\bar{v}}_{l, t}+n_{l, t+1} \hat{\bar{v}}_{l, t+1}+n_{l, t+2} \hat{\bar{v}}_{l, t+2}}{n_{l, t-2}+n_{l, t-1}+n_{l, t}+n_{l, t+1}+n_{l, t+2}}
$$

$$
\operatorname{SDSP\hat {D}} \operatorname{ANE}_{l, t}=\sqrt{\sum_{s=t-2}^{t+2} n_{l, s}\left(\hat{\bar{v}}_{l, s}-\overline{\bar{v}}_{150 \mathrm{sec} l, s}\right)^{2} / \sum_{s=t-2}^{t+2} n_{l, s}}
$$

where $\overline{\bar{v}}_{150 \text { sec } l, t}$ is the count-weighted average speed during the 150-second interval, and $n_{l, t}$ and $\hat{\bar{v}}_{l, t}$ are as defined earlier (Equation 4).

Equation 6 estimates the standard deviation ( $S D S P \hat{D} L A N E_{l, t}$ ) of every 150-second interval's middle speed profile (i.e., that of its third 30 -second interval). Thus, these estimates can vary every 30 seconds, even though the base assumption involves stationary 150 -second traffic speeds. If traffic conditions are not stationary, as in evolving traffic, actual speed variations - and thus standard deviations - are likely to be lower. ${ }^{14}$

Estimation of variations in average speeds across lanes is more straightforward than that within lanes. Average within-lane speeds and counts during each 30-second interval can be used as follows:

$$
\overline{\bar{v}}_{\text {accrosslanes }, t}=\frac{\sum_{l} n_{l, t} \hat{\bar{v}}_{l, t}}{\sum_{l} n_{l, t}}
$$


Freeway Speeds

Table 1: Example g-Factors Values from Orange County Freeways

\begin{tabular}{|c|c|c|c|c|c|c|}
\hline Route & $\begin{array}{c}\text { Milepost, } \\
\text { Time of Day, } \\
\text { \& Date }\end{array}$ & Lane \# & $\begin{array}{l}\text { Min } \\
\text { (ft.) }\end{array}$ & $\begin{array}{c}\text { Max } \\
\text { (ft.) }\end{array}$ & $\begin{array}{c}\text { Mean } \\
\text { (ft.) }\end{array}$ & $\begin{array}{l}\text { Std. Dev. } \\
\text { (ft.) }\end{array}$ \\
\hline \multirow{5}{*}{ Interstate 5} & \multirow{5}{*}{$\begin{array}{c}19.98(\mathrm{NB}) \\
17: 18-17: 44 \\
\text { Jan. } 31,1998\end{array}$} & 1 & 12.09 & 12.11 & 12.10 & .00744 \\
\hline & & 2 & 11.10 & 11.10 & 11.10 & .00000 \\
\hline & & 3 & 16.62 & 17.38 & 17.06 & 24978 \\
\hline & & 4 & 15.88 & 16.42 & 16.18 & .17783 \\
\hline & & 5 & 16.31 & 16.77 & 16.58 & 17373 \\
\hline \multirow{5}{*}{ Interstate 405} & \multirow{5}{*}{$\begin{array}{c}12.55(\mathrm{NB}) \\
14: 27-14: 53 \\
\text { Jan. } 13,1998\end{array}$} & 1 & 10.96 & 10.99 & 10.97 & .00891 \\
\hline & & 2 & 21.17 & 21.61 & 21.38 & .13787 \\
\hline & & 3 & 19.77 & 20.09 & 19.94 & .09583 \\
\hline & & 4 & 16.95 & 17.54 & 17.20 & 17198 \\
\hline & & 5 & 16.38 & 17.08 & 16.70 & 22373 \\
\hline \multirow{4}{*}{ State Route 22} & \multirow{4}{*}{$\begin{array}{c}9.77(\mathrm{WB}) \\
8: 47-9: 13 \\
\text { Jan. } 6,1998\end{array}$} & 1 & 24.78 & 24.86 & 24.82 & .02966 \\
\hline & & 2 & 20.89 & 20.95 & 20.92 & .02053 \\
\hline & & 3 & 19.52 & 19.70 & 19.66 & .05322 \\
\hline & & 4 & 19.77 & 19.93 & 19.85 & .05787 \\
\hline \multirow{4}{*}{ State Route 55} & \multirow{4}{*}{$\begin{array}{c}4.65(\mathrm{SB}) \\
4: 02-4: 28 \\
\text { Jan. 3, } 1998\end{array}$} & 1 & 44.43 & 44.94 & 44.73 & .16760 \\
\hline & & 2 & 31.68 & 31.96 & 31.80 & .10888 \\
\hline & & 3 & 23.02 & 24.31 & 23.70 & .47654 \\
\hline & & 4 & 36.13 & 36.69 & 36.42 & .17883 \\
\hline \multirow{5}{*}{ State Route 57} & \multirow{5}{*}{$\begin{array}{c}16.17(\mathrm{NB}) \\
19: 07-19: 33 \\
\text { Jan. 5, } 1998\end{array}$} & 1 & 19.55 & 19.66 & 19.58 & .03299 \\
\hline & & 2 & 18.84 & 19.20 & 18.99 & .11294 \\
\hline & & 3 & 19.98 & 20.58 & 20.26 & .19344 \\
\hline & & 4 & 15.56 & 15.74 & 15.63 & .05403 \\
\hline & & 5 & 12.34 & 12.50 & 12.43 & .05301 \\
\hline \multirow{5}{*}{ State Route 91} & \multirow{5}{*}{$\begin{array}{c}6.49 \text { (WB) } \\
2: 22-2: 48 \\
\text { Jan. } 1,1998\end{array}$} & 1 & 21.65 & 22.06 & 21.92 & .13871 \\
\hline & & 2 & 21.42 & 21.67 & 21.54 & .07457 \\
\hline & & 3 & 24.17 & 24.46 & 24.32 & .09807 \\
\hline & & 4 & 18.58 & 19.00 & 18.88 & .12976 \\
\hline & & 5 & 22.51 & 22.93 & 22.79 & .14326 \\
\hline
\end{tabular}

Source: PeMS (2002).

$$
\operatorname{SDACROSSLN} N_{t}=\sqrt{\sum_{l}\left(\hat{\bar{v}}_{l, t}-\overline{\bar{v}}_{\text {accrosslanes }, t}\right)^{2} \cdot n_{l, t} / \sum_{l} n_{l, t}}
$$

where $S D A C \hat{R} O S S L N_{t}$ is the estimate of standard deviation in average within-lane speeds across lanes in time interval $t$.

Together, within-lane and across-lane (or "between-lane") information on speed variation provides information on overall, road-section speed variations. Using within and between sums of squared deviations (WSS and $B S S$ ) from within-lane and across-lane grand mean speeds, one has the following:

$$
W S S_{t}=\sum_{l} n_{l, t} \cdot\left(\hat{\bar{v}}_{l, t}-\overline{\bar{v}}_{150 \sec l, t}\right)^{2}
$$




$$
\begin{aligned}
& B S S_{t}=\sum_{l} n_{l, t} \cdot\left(\hat{\bar{v}}_{l, t}-\overline{\bar{v}}_{\text {accrosslanes }, t}\right)^{2} \\
& \operatorname{TSS}_{t}=W S S_{t}+B S S_{t} \\
& \operatorname{SDSPDSXN}_{t}=\sqrt{\frac{T S S_{t}}{\sum_{l} n_{l, t}}}
\end{aligned}
$$

As a result of these operations, one has estimates of within-lane speed variation, across-lane speed variation, and total speed variation, for every road section instrumented with loop detectors. Any one and all three measures may be relevant for crash analysis, so all three are modeled here. ${ }^{15}$

\section{METHODOLOGY}

This work's objective is to find relationships among speeds, speed variation (measured as standard deviation), and crash likelihood. Ordinary least squares (OLS), weighted least squares (WLS), and binomial regression models were used, while controlling for weather and lighting conditions, lane position, and other key variables.

Based on simple rules of variance for mean estimates, average within-lane speed observations are weighted by the vehicle counts used in their computation. ${ }^{16}$ Non-constant variation of these estimated values is called heteroskedasticity. The squared residuals of an OLS regression can be studied for indications of such variation. As expected, those squared residuals for within-lane and section average speeds fell with traffic count, so the theoretically applicable weight of count (VOL and VOLUME, respectively) was used. ${ }^{17}$ When weights are appropriately chosen, WLS results offer more efficient parameter estimates than OLS (Greene 2000).

In addition to OLS models of section-based speed averages and standard deviations in speeds, and a WLS model of within-lane speed average, binomial models of crash likelihood were explored. If crashes are precipitated by special speed patterns, these features may be evident in the data, in the moments before a crash. The data set's time-till-crash variable (TMTLCRSH) is the difference between the reported crash time and the traffic observation time. ${ }^{18}$ Based on the time-till-crash estimates, indicator variables of whether the crash occurred within a certain period (three minutes, five minutes, and 10 minutes) of the observed traffic were coded. In the binomial models of crash likelihood, these indicator variables served as the response variable, $Y$ :

$$
\begin{aligned}
& \operatorname{Prob}(Y \quad 1) \frac{e^{\beta^{\prime} X}}{1+e^{\beta^{\prime} X}} \\
& \operatorname{Prob}(Y=0)=\frac{1}{1+e^{\beta^{\prime} X}}
\end{aligned}
$$

where control variables $X$ are defined as in Tables 2 and 5. From the estimated values of their coefficients, $\beta$, one can appraise the predicted direction and magnitude of their effects on the shortterm likelihood of crash occurrence. It was hoped that these binomial models would bear some fruit. However, it is the models of speed and speed variation that provided the most useful results.

\section{RESULTS}

Tables 2 and 5 summarize the data used to estimate effects of speed and its variations on crash occurrence while controlling for a variety of factors that are expected to influence driver speed choices, such as roadway features, environmental conditions, and traffic characteristics. Tables 4 and 8 provide model results for average within-lane and section speeds. Results for standard deviations of speeds, within-lanes, across-lanes, and in total, are shown in Tables 3, 6, and 7. Crash- 
Freeway Speeds

likelihood model results are not provided because they perform little better than a constants-only model.

All tables provide a column for standardized coefficient (Std. Coef.) estimates, which represent the number of standard deviation changes in the response variables (speed and speed standard error) that would be expected following a one-standard deviation change in the associated explanatory variable. These offer analysts a sense of the practical significance of all control covariates. All potential control covariates are included in the initial model's tabled results; final model specifications (shown alongside) emerged from a process of stepwise elimination, whereby statistically insignificant control variables (those having p-values greater than 0.10) were removed, one-by-one.

As expected, traffic density plays a critical role in virtually all model results, reducing travel speeds and generally moderating speed variation. More dense traffic conditions mean less room for crash avoidance, causing drivers to proceed more cautiously, slow down and synchronize their speed choices (as independent speed choice becomes difficult). Also as expected, more lanes result in higher average speeds, by permitting greater maneuverability and flexibility in driver speed choices. As anticipated, greater speed variations are estimated to occur in the outer, right-side lanes, due to the presence of ramps, slow vehicles, and weaving maneuvers. Slower speeds generally are witnessed along wet pavements and in the vicinity of obstructions and construction zones (as expected, due to driver concerns for safety in such locations). Finally, an obvious anticipation of higher speeds on higher design-speed facilities (though all roadways in this data set shared the same posted speed limit) was discerned in the empirical results. Other than these control variables, no clear expectations of behavioral response existed on the part of the researchers. While some may expect increasing variability in recorded traffic speeds to signal the onset of crash conditions, no results - in any of the model specifications (Tables 3, 4, 6, 7, and 8) - suggest that vehicle speeds or speed variations rise (or fall) near the reported time of crash. Essentially, it may be very difficult to anticipate the onset of a crash, based on loop detector data. The following discussion provides more detail on these and other relationships apparent in the various speed and speed variance behaviors.

Table 3's results suggest higher (free-flow) speeds occur on four-lane and five-lane (oneway) freeways than on three-lane freeways: ${ }^{19}$ average speeds on five-lane (one-way) freeways are estimated to be $3.81 \mathrm{mph}$ faster than those on three-lane freeways, everything else constant. And those on four-lane sections are estimated to be $2.16 \mathrm{mph}$ higher. Essentially, drivers have more opportunity to operate the vehicle at their preferred speeds when there are more lanes to choose from. These empirical results (3.81 and $2.16 \mathrm{mph}$ ) are consistent with, but $27 \%$ and $44 \%$ higher than, the HCM-suggested adjustments of 3.0 and $1.5 \mathrm{mph}$ (TRB 2000).

Also according to Table 3, the lowest average speeds arise in the next-to-right-side lane, and, as expected, the inside lanes (far left) have the highest average speeds. Traffic in the left-side lanes travels, on average, $7.41 \mathrm{mph}(5.25-(-2.16)=7.41) \mathrm{mph}$ faster than that in the next-to-far-right lanes. The HCM offers no information in this regard, making these results all the more useful for the transportation engineering community.

Table 4 suggests the highest speed variations (averaging $2.68 \mathrm{mph}$ higher) can be found in the far right-side lane. As noted earlier, those far-right lanes tend to have many weaving, merging and diverging maneuvers (from the left-side lanes and the far-right ramps and auxiliary lanes) as well as the section's slowest vehicles, so these results are consistent with expectations. Within-lane speed variation tends to rise with average speeds, and average within-lane speeds rise with number of lanes; however, the highest within-lane standard deviations are predicted on four-lane sections (as shown in Table 4, and assuming everything else constant). The results also indicate higher withinlane speed variability accompanies higher average speeds, and the presence of construction zones. In some contrast, Tables 6 and 7's estimates do not imply that higher across-lane or total speed variability accompanies higher average speeds. Evidently, problem perspective is important: speed variations within lanes can exhibit very different relationships from those that exist across lanes. Of course, it is probably within-lane variation that is more likely to provoke a crash than across-lane 
variation, but both may be relevant for safety analysis, particularly when lane changes are taking place.

As anticipated, model results suggest higher traffic densities result in lower average within-lane speeds and higher within-lane speed variation (Tables 3 and 4), while producing lower across-lane speeds and speed variation, and lower overall speed variations (Table 6, 7 and 8). As alluded to earlier, the reason for such results is felt to be that tight spacings (high densities) lead to greater driver caution, via use of lower speeds. They also require greater coordination of driver speeds, within each lane, since following drivers cannot afford to collide with those in front but want to travel as fast as possible, though conditions are relatively congested. Across lanes, however, traffic congestion (and thus density) can result in less speed coordination, as shockwaves propagate back and forth lane by lane, and right-side lanes may back up, slowing to a crawl, while left-side lanes continue to flow.

The results in Tables 3 and 8 also indicate that people drive slowest on freeways at night and without the benefits of streetlights, as compared to other lighting conditions. And they drive faster on higher design-speed sections, as one would expect. Within-lane and total speed variation (Tables 4 and 7, respectively) rise substantially under nighttime, streetlight conditions (by 4.129 and 4.224 mph, respectively), much more so than under no-streetlight nighttime conditions (1.789 and 0.786 $\mathrm{mph}$ ). The presence of lighting may provide great confidence to a subset of drivers, who then drive faster, thereby widening the range of speed choices under such nighttime conditions.

Within-lane and total speed variations also rise with design speeds, suggesting that some drivers are not comfortable with and/or do not take advantage of the higher-design conditions. The withinlane and total speed standard deviations are predicted to rise $1.8 \mathrm{mph}$ (Table 4) and $4.6 \mathrm{mph}$ (Table 7), respectively, for every $10 \mathrm{mph}$ increase in design speed.

As expected, average speeds are lower on roads that are wet or have obstructions (Tables 3 and 8), due to driver safety considerations. Within-lane speeds tend to fall $4.72 \mathrm{mph}$ on wet roads, as compared to dry roads, and across-lane speeds drop $4.77 \mathrm{mph}$. However, within-lane speed variations are higher when obstructions are present (Table 4), perhaps because of variation in driver familiarity and response to such conditions. The increases in within-lane speed variation and total speed variation due to roadway obstructions are estimated to average $6.02 \mathrm{mph}$ (Table 4) and 2.38 mph (Table 7), respectively.

Perhaps most interesting is the fact that the time-till-crash variables offer no predictive power in any of the speed and speed variation models (Tables 3, 4, 6, 7 and 8). And, as previously mentioned, the crash-likelihood regressions (for three minute, five minute, and 10 minute cases) are not statistically significant (and thus not presented in tabular form). This set of disappointing results is probably due to two key factors: First, the reported crash times may be off by five minutes or more, in many cases. Second, a lot can happen in 30 seconds, so the temporal aggregation inherent in the loop detector traffic reports obscures specific crash-precipitating events. However, it also may be that most speed information says little about crash occurrence, and other factors are at play, provoking crashes. Of course, speeds remain basic to crash severity, and may be fundamental to the types of crashes that occur (e.g., rear-end versus rollover crashes). 


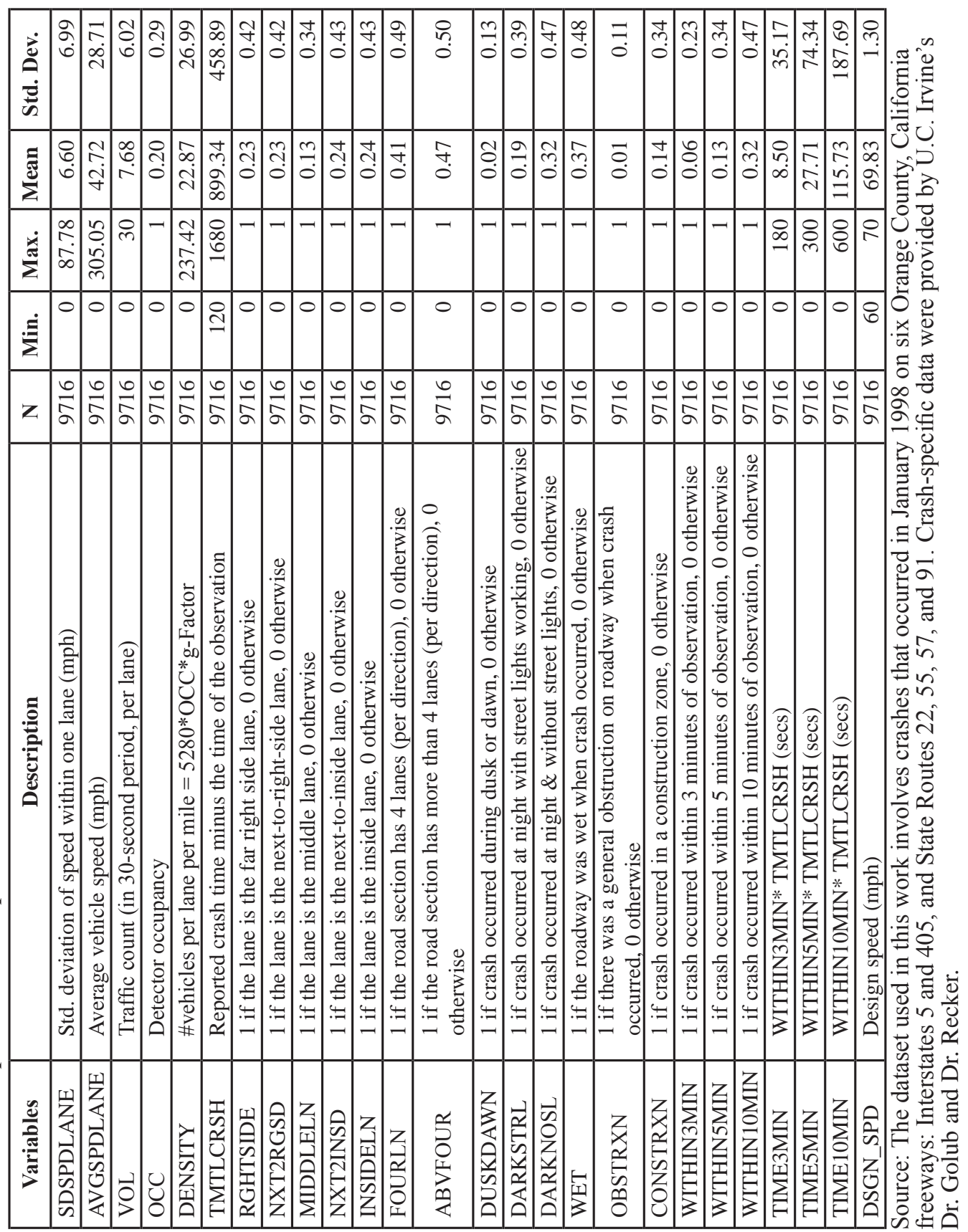


Table 3: Weighted Least Squares Regression Results of Within-Lane Average Speeds

\begin{tabular}{|c|c|c|c|c|c|c|c|c|}
\hline \multirow{2}{*}{ Variables } & \multicolumn{4}{|c|}{ Initial Model } & \multicolumn{4}{|c|}{ Final Model } \\
\hline & Coef. & Std. Err. & Std. Coef. & P-value & Coef. & Std. Err. & Std. Coef. & P-value \\
\hline CONSTANT & 30.021 & 7.446 & & 0.000 & 29.79 & 7.437 & & 0.000 \\
\hline FOURLN & 2.126 & 0.455 & 0.0363 & 0.000 & 2.156 & 0.452 & 0.0368 & 0.000 \\
\hline ABVFOUR & 3.837 & 0.491 & 0.0668 & 0.000 & 3.811 & 0.481 & 0.0664 & 0.000 \\
\hline DUSKDAWN & 0.566 & 0.864 & 0.00256 & 0.512 & & & & \\
\hline DARKSTRL & -3.477 & 0.396 & -0.0472 & 0.000 & -3.516 & 0.39 & -0.0478 & 0.000 \\
\hline DARKNOSL & -4.73 & 0.301 & -0.0774 & 0.000 & -4.748 & 0.294 & -0.0777 & 0.000 \\
\hline WET & -4.781 & 0.302 & -0.0799 & 0.000 & -4.723 & 0.288 & -0.0790 & 0.000 \\
\hline OBSTRXN & -9.096 & 1.203 & -0.0349 & 0.000 & -9.094 & 1.203 & -0.0348 & 0.000 \\
\hline CONSTRXN & -0.05136 & 0.464 & -0.000608 & 0.912 & & & & \\
\hline RGHTSIDE & -1.093 & 0.544 & -0.0160 & 0.045 & -1.098 & 0.544 & -0.0161 & 0.043 \\
\hline NXT2RGSD & -2.162 & 0.426 & -0.0316 & 0.000 & -2.164 & 0.426 & -0.0317 & 0.000 \\
\hline MIDDLELN & 1.689 & 0.432 & 0.0200 & 0.000 & 1.686 & 0.432 & 0.0200 & 0.000 \\
\hline NXT2INSD & 3.551 & 0.431 & 0.0519 & 0.000 & 3.541 & 0.431 & 0.0518 & 0.000 \\
\hline INSIDELN & 5.254 & 0.53 & 0.0787 & 0.000 & 5.247 & 0.529 & 0.0786 & 0.000 \\
\hline DSGN_SPD & 0.623 & 0.106 & 0.0282 & 0.000 & 0.626 & 0.106 & 0.0283 & 0.000 \\
\hline TIME3MIN & -0.00226 & 0.004 & -0.00277 & 0.557 & & & & \\
\hline TIME5MIN & -0.00028 & 0.002 & -0.000725 & 0.88 & & & & \\
\hline TIME10MIN & 0.000169 & 0.001 & 0.00110 & 0.799 & & & & \\
\hline DENSITY & -0.617 & 0.005 & -0.580 & 0.000 & -0.617 & 0.005 & -0.580 & 0.000 \\
\hline R-sqrd & & & & .626 & & & & .626 \\
\hline Adjust R-sqrd & & & & .625 & & & & .625 \\
\hline Num. of Obs. & & & & 9716 & & & & 9716 \\
\hline
\end{tabular}

Note: Italics indicate the most practically significant variables, based on standardized coefficient values. 
Freeway Speeds

Table 4: Ordinary Least Squares Regression Results of Within-Lane Speed Variation

\begin{tabular}{|c|c|c|c|c|c|c|c|c|}
\hline \multirow{2}{*}{ Variables } & \multicolumn{4}{|c|}{ Initial Model } & \multicolumn{4}{|c|}{ Final Model } \\
\hline & Coef. & Std. Err. & Std. Coef. & P-value & Coef. & Std. Err. & Std. Coef. & P-value \\
\hline CONSTANT & -14.198 & 3.463 & & 0.000 & -13.847 & 3.45 & & 0.000 \\
\hline FOURLN & 1.785 & 0.243 & 0.125 & 0.000 & 1.52 & 0.149 & 0.107 & 0.000 \\
\hline ABVFOUR & 0.352 & 0.257 & 0.0252 & 0.170 & & & & \\
\hline DUSKDAWN & -2.778 & 0.447 & -0.0517 & 0.000 & -2.805 & 0.446 & -0.0522 & 0.000 \\
\hline DARKSTRL & 4.119 & 0.182 & 0.230 & 0.000 & 4.129 & 0.182 & 0.230 & 0.000 \\
\hline DARKNOSL & 1.783 & 0.15 & 0.120 & 0.000 & 1.789 & 0.15 & 0.120 & 0.000 \\
\hline WET & 1.73 & 0.149 & 0.119 & 0.000 & 1.764 & 0.147 & 0.121 & 0.000 \\
\hline OBSTRXN & 6.173 & 0.515 & 0.0971 & 0.000 & 6.018 & 0.498 & 0.0947 & 0.000 \\
\hline CONSTRXN & 1.135 & 0.232 & 0.0552 & 0.000 & 1.201 & 0.226 & 0.0584 & 0.000 \\
\hline AVGSPDLANE & 0.09484 & 0.004 & 0.390 & 0.000 & 0.09546 & 0.004 & 0.392 & 0.000 \\
\hline RGHTSIDE & 2.896 & 0.274 & 0.174 & 0.000 & 2.68 & 0.169 & 0.161 & 0.000 \\
\hline NXT2RGSD & 1.662 & 0.219 & 0.0999 & 0.000 & 1.51 & 0.153 & 0.0907 & 0.000 \\
\hline MIDDLELN & 1.105 & 0.221 & 0.0537 & 0.000 & 0.981 & 0.185 & 0.0477 & 0.000 \\
\hline NXT2INSD & -0.4 & 0.221 & -0.0240 & 0.071 & -0.56 & 0.153 & -0.0336 & 0.000 \\
\hline INSIDELN & 0.22 & 0.274 & 0.0135 & 0.422 & & & & \\
\hline DSGN_SPD & 0.179 & 0.049 & 0.0333 & 0.000 & 0.179 & 0.049 & 0.0333 & 0.000 \\
\hline TIME3MIN & -0.00095 & 0.002 & -0.00478 & 0.617 & & & & \\
\hline TIME5MIN & -0.00148 & 0.001 & -0.0157 & 0.108 & & & & \\
\hline TIME10MIN & 0.000162 & 0 & 0.00435 & 0.627 & & & & \\
\hline DENSITY & 0.000198 & 0 & 0.000765 & 0.000 & 0.000197 & 0.000 & 0.000761 & 0.000 \\
\hline R-sqrd & & & & .169 & & & & .168 \\
\hline Adjust R-sqrd & & & & .167 & & & & .167 \\
\hline Num. of Obs. & & & & 9716 & & & & 9716 \\
\hline
\end{tabular}

Note: Italics indicate the most practically significant variables, based on standardized coefficient values.

Table 5: Description of Section-Specific Variables

\begin{tabular}{|c|c|c|c|c|c|c|}
\hline Variables & Description & $\mathbf{N}$ & Min. & Max. & Mean & $\begin{array}{l}\text { Std. } \\
\text { Dev }\end{array}$ \\
\hline SDSPDSXN & Std. deviation of speed across \& within lanes (30-sec) & 2585 & 0 & 123.28 & 10.83 & 10.02 \\
\hline SDACROSSLN & Std deviation of speed across lanes (30-sec) & 2585 & 0 & 107 & 7.88 & 9.88 \\
\hline AVGSXNSPD & Average vehicle speeds across lanes (30-sec) & 2585 & 0 & 123.06 & 42.89 & 22.05 \\
\hline VOLUME & Sum of traffic counts across lanes $(30-\mathrm{sec})$ & 2585 & 0 & 83 & 32.18 & 19.94 \\
\hline DENSITY & $\begin{array}{l}\text { \#vehicles per lane per mile }=5280^{*} \mathrm{OCC}^{*} \mathrm{~g} \text {-Factor (where } \\
\mathrm{OCC}=\text { fraction of } 30 \mathrm{sec} . \text { period that detector is occupied) }\end{array}$ & 2585 & 0 & 144.47 & 23.88 & 21.58 \\
\hline TMTLCRSH & Reported crash minus the time of the observation & 2585 & 120 & 1680 & 900.08 & 458.94 \\
\hline FOURLN & 1 if the road section has 4 lanes (per direction), 0 ot & 2585 & 0 & 1 & 0.44 & 0.50 \\
\hline ABVFOUR & $\begin{array}{l}1 \text { if the road section has more than } 5 \text { lanes (per direction), } 0 \\
\text { otherwise }\end{array}$ & 2585 & 0 & 1 & 0.39 & 0.49 \\
\hline DUSKDAWN & 1 if crash occurred during dusk or dawn, 0 otherwise & 2585 & 0 & 1 & 0.02 & 0.14 \\
\hline DARKSTRL & $\begin{array}{l}1 \text { if crash occurred at night with street lights working, } 0 \\
\text { otherwise }\end{array}$ & 2585 & 0 & 1 & 0.19 & 0.39 \\
\hline DARKNOSL & 1 if crash occurred at night \& without street lights, 0 otherwise & 2585 & 0 & 1 & 0.30 & 0.46 \\
\hline WET & 1 if the roadway was wet when crash occurred, 0 otherwise & 2585 & 0 & 1 & 0.35 & 0.48 \\
\hline OBSTRXN & $\begin{array}{l}1 \text { if there is obstruction on roadway when crash occurred, } 0 \\
\text { otherwise }\end{array}$ & 2585 & 0 & 1 & 0.02 & 0.14 \\
\hline CONSTRXN & 1 if crash occurred in a construction zone, 0 otherwise & 2585 & 0 & 1 & 0.13 & 0.34 \\
\hline WITHIN3MIN & 1 if crash occurred within 3 minutes of observation, 0 otherwise & 2585 & 0 & 1 & 0.06 & 0.23 \\
\hline WITHIN5MIN & 1 if crash occurred within 5 minutes of observation, 0 otherwise & 2585 & 0 & 1 & 0.13 & 0.34 \\
\hline WITHIN10MIN & $\begin{array}{l}1 \text { if crash occurred within } 10 \text { minutes of observation, } 0 \\
\text { otherwise }\end{array}$ & 2585 & 0 & 1 & 0.32 & 0.47 \\
\hline TIME3MIN & WITHIN3MIN* TMTLCRSH (secs) & 2585 & 0 & 180 & 8.50 & 35.18 \\
\hline TIME5MIN & WITHIN5MIN* TMTLCRSH (secs) & 2585 & 0 & 300 & 27.77 & 74.43 \\
\hline TIME10MIN & WITHIN10MIN* TMTLCRSH (secs) & 2585 & 0 & 600 & 115.31 & 187.41 \\
\hline DSGN_SPD & Design speed (mph) & 2585 & 60 & 70 & 69.82 & 1.35 \\
\hline
\end{tabular}

Source: PeMS (2002). 
Freeway Speeds

Table 6: Ordinary Least Squares Regression Results of Across-Lane Speed Variation

\begin{tabular}{|c|c|c|c|c|c|c|c|c|}
\hline \multirow[b]{2}{*}{ Variables } & \multicolumn{4}{|c|}{ Initial Model } & \multicolumn{4}{|c|}{ Final Model } \\
\hline & Coeff. & Std. Err. & Stdz. Coeff. & P-value & Coeff. & Std. Err. & $\begin{array}{l}\text { Stdz. } \\
\text { Coeff. }\end{array}$ & $\begin{array}{c}\text { P- } \\
\text { value }\end{array}$ \\
\hline CONSTANT & 19.638 & 7.335 & & 0.007 & 19.61 & 7.262 & & 0.007 \\
\hline FOURLN & 1.161 & 0.43 & 0.0588 & 0.007 & 1.138 & 0.43 & 0.0576 & 0.008 \\
\hline ABVFOUR & -10.103 & 0.459 & -0.501 & 0.000 & -10.115 & 0.431 & -0.502 & 0.000 \\
\hline DUSKDAWN & -6.614 & 1.09 & -0.0937 & 0.000 & -6.247 & 1.039 & -0.0885 & 0.000 \\
\hline DARKSTRL & 0.104 & 0.445 & 0.00411 & 0.815 & & & & \\
\hline DARKNOSL & -0.405 & 0.366 & -0.0189 & 0.269 & & & & \\
\hline WET & 0.359 & 0.365 & 0.0174 & 0.326 & & & & \\
\hline OBSTRXN & -2.996 & 1.091 & -0.0425 & 0.006 & -3.02 & 1.076 & -0.0428 & 0.005 \\
\hline CONSTRXN & -0.379 & 0.605 & -0.0130 & 0.531 & & & & \\
\hline AVGSXNSPD & -0.29 & 0.01 & -0.647 & 0.000 & -0.29 & 0.01 & -0.647 & 0.000 \\
\hline DSGN_SPD & 0.207 & 0.106 & 0.0283 & 0.051 & 0.207 & 0.104 & 0.0283 & 0.047 \\
\hline TIME3MIN & 0.000798 & 0.004 & 0.00284 & 0.859 & & & & \\
\hline TIME5MIN & -0.00329 & 0.002 & -0.0248 & 0.131 & & & & \\
\hline TIME10MIN & $2.86 \mathrm{E}-05$ & 0.001 & 0.000543 & 0.971 & & & & \\
\hline DENSITY & -0.292 & 0.009 & -0.638 & 0.000 & -0.293 & 0.008 & -0.640 & 0.000 \\
\hline R-sqrd & & & & .470 & & & & .468 \\
\hline Adjust R-sqrd & & & & .467 & & & & .467 \\
\hline Num. of Obs. & & & & 2585 & & & & 2585 \\
\hline
\end{tabular}

Note: Italics indicate the most practically significant variables, based on standardized coefficient values.

Table 7: Ordinary Least Squares Regression Results of Total Section Speed Variation

\begin{tabular}{|c|c|c|c|c|c|c|c|c|}
\hline \multirow{2}{*}{ Variables } & \multicolumn{4}{|c|}{ Initial Model } & \multicolumn{4}{|c|}{ Final Model } \\
\hline & Coef. & Std. Err. & Std. Coeff. & P-value & Coef. & Std. Err. & Std. Coef. & P-value \\
\hline CONSTANT & -18.611 & 7.65 & & 0.015 & -18.666 & 7.646 & & 0.015 \\
\hline FOURLN & 1.369 & 0.449 & 0.0683 & 0.002 & 1.368 & 0.449 & 0.0683 & 0.002 \\
\hline ABVFOUR & 9.965 & 0.479 & 0.487 & 0.000 & 9.965 & 0.479 & 0.487 & 0.000 \\
\hline DUSKDAWN & -2.037 & 1.137 & -0.0285 & 0.073 & -2.039 & 1.137 & -0.0285 & 0.073 \\
\hline DARKSTRL & 4.223 & 0.464 & 0.164 & 0.000 & 4.224 & 0.464 & 0.164 & 0.000 \\
\hline DARKNOSL & 0.784 & 0.382 & 0.0360 & 0.04 & 0.786 & 0.382 & 0.0361 & 0.040 \\
\hline WET & -0.996 & 0.381 & -0.0477 & 0.009 & -0.996 & 0.381 & -0.0477 & 0.009 \\
\hline OBSTRXN & 2.381 & 1.137 & 0.0333 & 0.036 & 2.381 & 1.137 & 0.0333 & 0.036 \\
\hline CONSTRXN & -4.002 & 0.631 & -0.136 & 0.000 & -4.005 & 0.630 & -0.136 & 0.000 \\
\hline AVGSXNSPD & -0.04178 & 0.011 & -0.0919 & 0.000 & -0.0414 & 0.011 & -0.0911 & 0.000 \\
\hline DSGN_SPD & 0.461 & 0.111 & 0.0621 & 0.000 & 0.460 & 0.111 & 0.0620 & 0.000 \\
\hline TIME3MIN & -0.00144 & 0.005 & -0.00506 & 0.759 & & & & \\
\hline TIME5MIN & -0.00126 & 0.002 & -0.00936 & 0.579 & & & & \\
\hline TIME10MIN & -0.00012 & 0.001 & -0.00224 & 0.882 & & & & \\
\hline DENSITY & -0.169 & 0.009 & -0.364 & 0.000 & -0.169 & 0.009 & -0.364 & 0.000 \\
\hline R-sqrd & & & & .403 & & & & .403 \\
\hline Adjust R-sqrd & & & & .400 & & & & .400 \\
\hline Num. of Obs. & & & & 2585 & & & & 2585 \\
\hline
\end{tabular}

Note: Italics indicate the most practically significant variables, based on standardized coefficient values. 
Freeway Speeds

Table 8: Weighted Least Squares Regression Results of Section Average Speeds

\begin{tabular}{|c|c|c|c|c|c|c|c|c|}
\hline \multirow{2}{*}{ Variables } & \multicolumn{4}{|c|}{ Initial Model } & \multicolumn{4}{|c|}{ Final Model } \\
\hline & Coef. & Std. Err. & Std. Coeff. & P-value & Coef. & Std. Err. & Std. Coef. & P-value \\
\hline CONSTANT & -70.53 & 13.668 & & 0.000 & -71.361 & 13.644 & & 0.000 \\
\hline FOURLN & 1.928 & 0.684 & 0.0437 & 0.005 & 1.947 & 0.498 & 0.0441 & 0.000 \\
\hline ABVFOUR & 0.204 & 0.741 & 0.00453 & 0.783 & & & & \\
\hline DUSKDAWN & 1.938 & 1.596 & 0.0123 & 0.225 & & & & \\
\hline DARKSTRL & -4.522 & 0.729 & -0.0800 & 0.000 & -4.666 & 0.719 & -0.0825 & 0.000 \\
\hline DARKNOSL & -8.464 & 0.567 & -0.177 & 0.000 & -8.516 & 0.564 & -0.178 & 0.000 \\
\hline WET & -4.98 & 0.562 & -0.108 & 0.000 & -4.766 & 0.53 & -0.104 & 0.000 \\
\hline OBSTRXN & -8.353 & 2.217 & -0.0530 & 0.000 & -8.457 & 2.164 & -0.0537 & 0.000 \\
\hline CONSTRXN & 1.401 & 0.864 & 0.0216 & 0.105 & 1.476 & 0.832 & 0.0228 & 0.076 \\
\hline DSGN_SPD & 2.081 & 0.196 & 0.127 & 0.000 & 2.094 & 0.196 & 0.128 & 0.000 \\
\hline TIME3MIN & $-5.53 \mathrm{E}-03$ & 0.007 & -0.00882 & 0.438 & & & & \\
\hline TIME5MIN & $-3.26 \mathrm{E}-03$ & 0.003 & -0.0110 & 0.34 & & & & \\
\hline TIME10MIN & $6.44 \mathrm{E}-04$ & 0.001 & 0.00547 & 0.601 & & & & \\
\hline DENSITY & -0.705 & 0.012 & -0.690 & 0.000 & -0.707 & 0.012 & -0.692 & 0.000 \\
\hline R-sqrd & & & & .591 & & & & .591 \\
\hline Adjust R-sqrd & & & & .589 & & & & .589 \\
\hline Num. of Obs. & & & & 2585 & & & & 2585 \\
\hline
\end{tabular}

Note: Italics indicate the most practically significant variables, based on standardized coefficient values.

\section{CONCLUSIONS}

The purpose of this research is to illuminate average speed and speed variation patterns across lanes and environmental conditions and to identify any connection between such patterns and crash occurrence. Speeds are widely believed to be a key to understanding crash severity, and their variation has been argued to be fundamental to crash occurrence. However, in this study of speed information preceding injury and fatal crashes on Southern California freeways, no indication of changes in 30-second speed patterns emerged prior to crash occurrence. All models controlled for traffic conditions (including density), weather conditions, lighting conditions, lane geometry, and road surface conditions.

While no evidence emerged that supports a hypothesis of speed conditions influencing crash occurrence (probably due to data aggregation, crash-time reporting errors, local factors in the vicinity of crash site that are unobserved), there are many interesting results. For example, higher design speeds result in higher speed variation (as well as higher overall speeds). And higher withinlane speed variations accompany higher (within-lane) speeds. Traffic density is a key predictor, associated with significantly higher speed variations, but lower average speeds - as expected. Right-side lanes exhibit the greatest speed variation, while left-side lanes exhibit the highest average speeds. More lanes mean higher speeds, even higher than suggested by the Highway Capacity Manual. As expected, poor lighting conditions and wet pavement surface tend to slow traffic.

The key limitation of this work lies in its data. Essentially, all loop detectors, whether they are single or double, aggregate counts and occupancies to 20-second or longer intervals. Crashes are very rare events, so automated forms of traffic data collection are needed to associate the two. However, crash times are rarely known with great certainty and time-averaging obscures many odd speed events that may arise. In addition, single-loop detector data requires one to rely on effective length estimates for average speed prediction. Here, the g-factors vary every five minutes and are not based on the actual vehicles traversing a station in any given interval. Furthermore, without 
individual speed information, speed variation had to be inferred from the variation in average speeds over a series of intervals and over a series of lanes. This is a bold assumption. In this time of emerging technologies for traffic monitoring and data manipulation, it is hoped that coming data sets will illuminate any relationships between speed choice and crash occurrence. Europe is already encouraging moderate driving speeds to avoid the onset of forced-flow (or unstable) traffic conditions (Helbing and Huberman 1998, FHWA 1999, Helbing 2002, and Commonwealth of Australia 2002). The world may be able to moderate speeds to avoid crash occurrence.

\section{Acknowledgements}

The authors thank Thomas F. Golob and Wilfred Recker for generously sharing the crash and loop detector data, Young-Jun Kweon and Karl Petty for offering useful discussions related to the data and methods of analysis, Ms. Annette Perrone for editorial assistance, and anonymous reviewers for several helpful comments. The FHWA HSIS Lab's Yusuf Mohamedshah provided roadway design data, and National Highway Cooperative Research Program (NCHRP) Project 17-23 provided the financial support for this work.

\section{Endnotes}

1. A single loop detector has a single electronic resonant circuit which measures the change of inductance caused by metal bodies that pass over the loop. Basically, a single loop detector produces volume (the number of vehicles crossing the loop detector during a time interval $T$ ) and occupancy (the fraction of $T$ during which a vehicle “occupies"/lies above the loop).

2. Traffic flow equals traffic density multiplied by speed, and density equals occupancy divided by average vehicle length (assuming speeds and vehicle lengths are independent [Kockelman 1998]). Thus, traffic flow divided by occupancy is nearly proportional to speed, as long as vehicle lengths are relatively stable/constant.

3. This subset is all 55 crashes involving injury or death.

4. Upstream is defined as toward the direction from which vehicles come.

5. Off-ramps, on-ramps, and lane drops within 2,000 feet of the detectors could influence crash occurrence but are outside the scope of the paper.

6. All studied sections' speed limits are $65 \mathrm{mph}$ (Golob 2003c), so this invariable factor could not be controlled for in the analysis.

7. Double-loop detectors are the primary alternative to single loops. They are closely spaced and provide the time interval between a vehicle's arrival at each loop. Given the distance between the two loop heads, this information permits ready speed estimation. Dual loops also permit direct estimation of vehicle length, given the speed estimate and assuming an effective detection zone length of either or both detectors.

8. A constant-speed assumption during passage over a loop detector is reasonable here, given the short effective length of the detection zone (which is on the order of 25 feet).

9. Presence-type detectors detect vehicle presence by measuring changes in sensor signals. 
Freeway Speeds

10. Inductive loop detectors are "occupied" when able to detect the presence of metal bodies overhead. At the level of the pavement, their effective detection zones typically exceed their physical length. However, at the level of a vehicle's metal body, the effective zone length may differ. Depending on the placement and sensitivity of each detector, as well as vehicle body heights, effective lengths differ (Reno A\&E 2003).

11. Occupancy fraction is the portion of the 30 -second interval during which a vehicle lies above the loop.

12. For instance, Wang and Nihan's (2003) method requires a distribution of vehicle lengths and classifies vehicles into just two classes (short and long) in order to compute average speeds for both types.

13. Using these fixed-length assumptions, $6.32 \%$ of the average speed estimates exceeded 100 $\mathrm{mph}$, and $0.93 \%$ exceeded $120 \mathrm{mph}$. Only unreasonably low estimates of vehicle length could produce reasonable speed distribution estimates.

14. If the speed distributions "shift" over the 150-second interval, but retain their spread (or instantaneous variance), the data will suggest more variation than actually exists. If, instead, the means stay constant but variations change, estimates may be biased high or low for the middle 30-second interval's speed variation.

15. The database provides no information regarding crashes that start in one lane but end in another.

16. Since the variance of a sample average is inversely proportional to the sample size (assuming independent observations), the observational weights are these sample sizes (i.e., traffic counts). (See Greene 2000.)

17. Ideally, weights vary inversely with error-term variation. Since the variation of averages is proportional to the inverse of sample size (assuming independent observational units), this weight should apply here, at least in theory.

18. Since detector stations are within 2000 feet of all crashes, the travel times from detector to crash were negligible under most traffic conditions, relative to the 30 -second aggregation period. Thus, the time-till-crash variable does not adjust for this length discrepancy.

19. Five lanes was the maximum (one-way) freeway width found in the data set.

\section{References}

Adolf, D. M. Traffic Flow Fundamentals. Prentice Hall, Englewood Cliffs, New Jersey, 1990.

Aljanahi, A.A.M., A.H. Rhodes and A.V. Metcalfe. "Speed, Speed Limits and Road Traffic Accidents Under Free Flow Conditions.” Accident Analysis and Prevention 31 (1-2), (1999): 161-168.

Blincoe, L.J., A.G. Seay., E. Zaloshnja, T.R Miller,. E.O. Romano, S. Luchter, and R.S. Spicer. The Economic Impact of Motor Vehicle Crashes, 2000. NHTSA Technical Report, Report\#: HS809 446, 2002.

Bruce, R. H. “Improving Freeway Speed Estimates from Single-Loop Detectors.” Journal of Transportation Engineering (2002) : 58-67. 
Freeway Speeds

Caltrans. Manual of Traffic Accident Surveillance and Analysis System (TASAS). California Department of Transportation, Sacramento, California, 1993.

Cirillo, J.A. “Interstate System Accident Research Study II.” Interim Report II. Public Roads 35 (3), (1968): 71-75.

Coifman, B., S. Dhoorjaty, and Z. Lee. "Estimating Median Velocity Instead of Mean Velocity at Single Loop Detectors.” Transportation Research C 11(3-4),(2003):211-222.

Coifman, B. "Improved Velocity Estimation Using Single Loop Detectors." Transportation Research 35A (10), (2001): 863-880.

Commonwealth of Australia. Moving on Intelligent Transport Systems. House of Representatives, Standing Committee on Transportation and Regional Services. (2002) [Online]. Available: http:// www.aph.gov.au/house/committee/trs/itinq/report/report.pdf, July 26, 2003.

Davis, G.A. “Is the Claim that 'Variance Kills' an Ecological Fallacy?” Accident Analysis and Prevention 34 (3),(2002): 343-346.

Farmer, C.M., R.A. Retting, and A.K. Lund. "Changes in Motor Vehicle Occupant Fatalities After Repeal of the National Maximum Speed Limit.” Accident Analysis and Prevention 31 (5),(1999): 537-543.

FHWA. Innovative Traffic Control Technology and Practice in Europe. (1999) [Online]. Available: http://international.fhwa.dot.gov/pdfs/innovtce.pdf , July 25, 2003.

FHWA. Guidebook for the California State Data Files. Highway Safety Information System, Volume I: SAS file formats. Federal Highway Administration Report \#FHWA-RD-00-137, Washington, D.C., 2000.

Garber, J.J. and R Gadiraju., "Factors Affecting Speed Variance and its Influence on Accidents." Transportation Research Record No. 1213, (1989): 64-71.

Golob, T., and W. Recker. Relationships among Urban Freeway Accidents, Traffic Flow, Weather and Lighting Conditions. Institute of Transportation Studies Report UCI-ITS-WP-02-1. University of California, Irvine, 2002.

Golob, T., and W. Recker.. "A Method for Relating Type of Crash to Traffic Characteristics on Urban Freeways.” Paper presented at the 82nd Annual Meeting of the Transportation Research Board. Washington, D.C., January 12-16,2003.

Golob, T., W. Recker and V. Alvarez. "Safety Aspects of Freeway Weaving Sections." Paper presented at the 82nd Annual Meeting of the Transportation Research Board. Washington, D.C., January 12-16, 2003a.

Golob, T., W. Recker and V. Alvarez. "A Tool to Evaluate the Safety Effects of Changes in Freeway Traffic Flow." Paper presented at the 82nd Annual Meeting of the Transportation Research Board. Washington, D.C., January 12-16, 2003 b.

Golob, T., W. Recker and V.Alvarez. Freeway Safety as a Function of Traffic Flow. Working paper UCI-ITS-WP-03-2, 2003c.

Greene, W.H. Econometric Analysis, Fourth Edition. Prentice Hall, Upper Saddle River, New Jersey, 2000. 
Freeway Speeds

Helbing, D. and B.A. Huberman. "Coherent Moving States in Highway Traffic.” Nature 396 (6713), (1998): 738-740.

Helbing, D. "Order and Disorder in Traffic and Self-Driven Many-Particle Systems." AIP Conference Proceedings 622 (1), (2002): 239-250.

Jia, Z., C. Chen, B. Coifman, and P. Varaiya. "The PeMS Algorithms for Accurate, Real-time Estimates of G-factors and Speeds from Single-loop Detectors.” Presented at IEEE 4th International ITS Conference. Oakland, California, 2001.

Johansson, P. "Speed Limitation and Motorway Casualties: A Time Series Count Data Regression Approach.” Accident Analysis and Prevention, 28 (1), (1996): 73-87.

Joksch, H.C. "Velocity Change and Fatality Risk in A Crash: A Rule of Thumb." Accident Analysis and Prevention 25 (1), (1993): 103-104.

Kloeden, C.N., G. Ponte and A.J. McLean. Traveling Speed and the Risk of Crash Involvement on Rural Roads. Road Accident Research Unit. Adelaide University. Report No. CR 204 (2001). [Online]. Available: http://raru.adelaide.edu.au/ruralspeed, June 25, 2003.

Kloeden C.N., A.J. McLean and G. Glonek. Reanalysis of Traveling Speed and the Risk of Crash Involvement in Adelaide South Australia. Road Accident Research Unit. The University of Adelaide. Report No. CR 207 (2002). [Online]. Available: http://raru.adelaide.edu.au/speed, June 27, 2003.

Kockelman, K. "Changes in the Flow-Density Relation due to Environmental, Vehicle, and Driver Characteristics.” Transportation Research Record No. 1644, (1998): 47-56.

Kockelman, K. and Y.J. Kweon. "Driver Injury Severity and Vehicle Type: An Application of Ordered Probit Models." Accident Analysis and Prevention 34 (3), (2002): 313-321.

Kockelman, K., J. Bottom, Y.J. Kweon, J. Ma and X. Wang. Safety Impacts and Other Implications of Raised Speed Limits on High-Speed Roads. National Cooperative Highway Research Program (NCHRP) Report 17-23, 2006.

Lave, C. "Speeding, Coordination, and the 55-mph Limit.” The American Economic Review 75 (5), (1985): 1160-1164.

Lave, C. and P. Elias. “Did the 65 mph Speed Limit Save Lives?” Accident Analysis and Prevention 26 (1), (1994): 49-62.

Navon, D. “The Paradox of Driving Speed: Two Adverse Effects on Highway Accident Rate.” Accident Analysis and Prevention 35 (3), (2003):361-367.

Ossiander, E.M. and P. Cummings. "Freeway Speed Limits and Traffic Fatalities in Washington State.” Accident Analysis and Prevention 34 (1), (2002):13-18.

PeMS “Freeway Performance Measurement Project." (2002) [Online]. Available: http://pems. eecs.berkeley.edu/login.phtml, November 11, 2002.

Pushkar, A., F.L Hall, and J.A.Acha-Daza. "Estimation of Speeds from Single-loop Freeway Flow and Occupancy Data Using CUSP Catastrophe Theory Model." Transportation Research Record 1457, (1994):149-157. 
Reno A\&E Inductive Loop Detectors. Reno A\&E Consultants, Reno, Nevada. (2003) [Online]. Available: http://www.renoae.com/Documentation/Inductive\%20Loop\%20Detectors\%20\%200324-03.pdf, July 25, 2003.

Solomon, D. Accidents on Main Rural Highways Related to Speed, Driver, and Vehicle. Federal Highway Administration, Washington, D.C., 1964 (Reprinted 1974).

TRB Highway Capacity Manual. Transportation Research Board, National Research Council Washington, D.C., 2000.

U.S. Department of Transportation, National Highway Traffic Safety Administration, National Center for Statistics and Analysis, Traffic Safety Facts 2004. DOT HS 809919 Washington, D.C., Table 53, 2005.

Vernon, D.D., L.J. Cook, K.J Peterson and J.M.Dean. "Effect of Repeal of the National Maximum Speed Limit Law on Occurrence of Crashes, Injury Crashes, and Fatal Crashes on Utah Highways." Accident Analysis and Prevention (2003) In press.

Wang, Y. and N. Niha. "Freeway Traffic Speed Estimation with Single Loop Outputs." Transportation Research Record 1727, (2000): 120-126.

Wang, Y. and N.L. Nihan. "Can Single-loop Detectors do the Work of Dual-loop Detectors?" Journal of Transportation Engineering ASCE, 129 (2), (2003): 169-176.

Jianming Ma holds a Ph.D. in civil engineering from the University of Texas at Austin and works for the Washington D.C. Department of Transportation. His expertise and interests are in the areas of traffic crash prediction, traffic data integration and analysis, and travel demand forecasting.

Kara Kockelman is an associate professor of civil, architectural \& environmental engineering and William J. Murray Jr. Fellow at the University of Texas at Austin, Kockelman is a registered professional engineer and holds $P h D, M S$, and BS degrees in civil engineering, a masters of city planning, and a minor in economics from the University of California at Berkeley. Her primary research interests include the statistical modeling of urban systems (including models of travel behavior, trade, and location choice), the economic impacts of transport policy, crash occurrence and consequences, and transport policymaking. 